\title{
The degree of microsatellite instability predicts response to PD-1 blockade immunotherapy in mismatch repair-deficient/ microsatellite instability-high colorectal cancers
}

\author{
Qiao-Xuan Wang ${ }^{1,2}$, Chun-Hua Qu ${ }^{1,3}$, Yuan-Hong Gao ${ }^{1,2}$, Pei-Rong Ding ${ }^{1,4}$, Jing-Ping Yun ${ }^{1,3}$, Dan Xie ${ }^{1,3^{*}}$ \\ and Mu-Yan Cai ${ }^{1,3^{*}}$
}

\begin{abstract}
The development of programmed cell death-1 inhibitor (PD-1) has shed light on the treatment of tumors with deficiencies in DNA mismatch repair system or microsatellite instability (dMMR/MSI). However, predicting the subset in this group that will benefit from PD-1 blockade remains a challenge. In this study, we aimed to investigate the relationship between the degree of microsatellite instability and the responses to anti-PD-1 immunotherapy. 33 patients with colorectal adenocarcinoma who had a known MSI status and received anti-PD-1 immunotherapy were included. PCR results for MSI of the whole cohort were collected and treatment response was evaluated. Our data indicated that objective response rate (ORR) in instability-high group (instability loci $\geq 3$ ) was significantly higher than ORR in instability-intermediate group (13/16 versus $6 / 17, P=0.008)$. Besides, patients in instability-high group had significant longer progression-free survival (log-rank test, $P=0.004$ ), and a significant increase in $T$ lymphocyte infiltration and cytolytic activity in tumors. Future study might implement the intensity of microsatellite instability for more delicate selection for anti-PD-1 therapy in patient with dMMR/MSI-H tumors.
\end{abstract}

Keywords: dMMR/MSI-H, Anti-PD-1 immunotherapy, Colorectal cancer

\section{To the Editor}

Defects in DNA mismatch repair (dMMR) promote a frequent insertion and/or deletion hypermutable state in nucleotide repeats regions termed microsatellite instability-high (MSI-H) [1]. Colorectal cancers (CRCs) with $\mathrm{dMMR} / \mathrm{MSI}-\mathrm{H}$ have favorable response to the programmed cell death-1 (PD-1) blockade immunotherapy [2]. However, there are still $45-70 \%$ of such tumors which do not respond to immune checkpoint blockade, so predicting the subset that will benefit from PD-1 blockade

\footnotetext{
*Correspondence: xiedan@sysucc.org.cn; caimy@sysucc.org.cn ${ }^{1}$ Collaborative Innovation Center for Cancer Medicine, State Key Laboratory of Oncology in South China, Sun Yat-Sen University Cancer Center, No. 651, Dongfeng Road East, Guangzhou 510060, China Full list of author information is available at the end of the article
}

remains a challenge [3-5]. In the current study, we aimed to evaluate whether the degree of microsatellite instability can predict the diversity of responses to anti-PD-1 immunotherapy in dMMR/MSI-H colorectal cancers.

\section{Methods}

Patients' data were collected from a prospectively maintained database in Sun Yat-sen University Cancer Center, Guangzhou, China. Inclusion criteria were as follows: (1) pathologically confirmed colorectal adenocarcinoma; (2) a known MSI status; (3) received at least one dose of anti-PD-1 therapy. Patients with tumors demonstrating no instability loci (microsatellite stable, MSS) were excluded, except for those whose tumor was proved to be dMMR. MSI or dMMR status

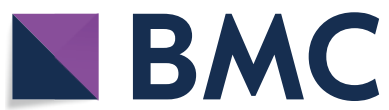

(c) The Author(s) 2021. This article is licensed under a Creative Commons Attribution 4.0 International License, which permits use, sharing, adaptation, distribution and reproduction in any medium or format, as long as you give appropriate credit to the original author(s) and the source, provide a link to the Creative Commons licence, and indicate if changes were made. The images or other third party material in this article are included in the article's Creative Commons licence, unless indicated otherwise in a credit line to the material. If material is not included in the article's Creative Commons licence and your intended use is not permitted by statutory regulation or exceeds the permitted use, you will need to obtain permission directly from the copyright holder. To view a copy of this licence, visit http://creativeco mmons.org/licenses/by/4.0/. The Creative Commons Public Domain Dedication waiver (http://creativecommons.org/publicdomain/ zero/1.0/) applies to the data made available in this article, unless otherwise stated in a credit line to the data. 
was prospectively determined using the American National Cancer Institute-recommended Polymerase Chain Reaction (PCR) for MSI or immunohistochemistry (IHC) for dMMR. IHC analyses of CD3 and CD8 were performed using the standard methods on pretreatment specimens. The ethical committees in our center approved this study procedure and waive the necessity of informed consult.

Treatment response was evaluated every two cycles of treatment according to RECIST v1.1. Objective response rate (ORR) was defined as the portion of patients with complete response (CR) or partial response (PR). Progression-free survival (PFS) was calculated from the date of initial anti-PD-1 treatment to either the date of the first progression or death due to CRC. ORRs between groups were compared by $x^{2}$ test. PFS was estimated using the Kaplan-Meier method and compared between groups with the log-rank test. Multivariate analyses were performed using the Cox proportional hazards model.

\section{Results}

Thirty-three patients were included in the study, with eighteen men and a median age of 45 years (range, 19 to 67). Baseline characteristics were shown in Table 1. Two patients were diagnosed with stage II disease (one local recurrent), seven patients were with stage III disease, while 24 patients were with stage IV disease. Among them, nineteen patients had received $\geq 2$ lines of prior systemic therapies before anti-PD-1 immunotherapy. Thirteen patients were treated with a single-agent antiPD-1 antibody, and the median cycles of therapy given were 8 (range $1-31$ ).

As shown in Table 2, we found that three patients identified as d-MMR but with microsatellite stability (MSS) disease had no response to anti-PD-1 treatment. By contrast, all patients with five instability loci achieved PR or CR (Additional file 1: Figure S1). To investigate the relationship between the degree of MSI and responses to anti-PD-1 therapy, we classified the patients into instability-intermediate (instability loci $<3$ ) and instabilityhigh subgroups (instability loci $\geq 3$ ) according to the

Table 1 Baseline characteristics of patients according to the degrees of MSI

\begin{tabular}{|c|c|c|c|}
\hline Variables & Instability loci < 3 & Instability loci $\geq 3$ & $P$ value \\
\hline$n$ & 17 & 16 & \\
\hline Age-median (range), year & $45.0(19.0-64.0)$ & $45.5(30.0-67.0)$ & 0.783 \\
\hline Sex-n & & & 0.112 \\
\hline Male & 7 & 11 & \\
\hline Female & 10 & 5 & \\
\hline Tumor stage-n & & & 0.619 \\
\hline$\|/\|$ & 4 & 5 & \\
\hline IV & 13 & 11 & \\
\hline Lines of therapy-n & & & 0.119 \\
\hline First line & 5 & 9 & \\
\hline Second or late line & 12 & 7 & \\
\hline Combined with chemotherapy-n & & & 0.055 \\
\hline Yes & 13 & 7 & \\
\hline No & 4 & 9 & \\
\hline
\end{tabular}

Table 2 Treatment response and ORR of patients stratified by the number of instability loci

\begin{tabular}{|c|c|c|c|c|c|c|}
\hline Number of instability loci & Number of cases & $\mathrm{CR}^{*}$ & PR & SD & PD & ORR \\
\hline 0 & 3 & 0 & 0 & 2 & 1 & 0 \\
\hline 1 & 5 & 0 & 0 & 2 & 3 & 0 \\
\hline 2 & 9 & 2 & 4 & 1 & 2 & 0.67 \\
\hline 3 & 9 & 5 & 2 & 1 & 1 & 0.78 \\
\hline 4 & 4 & 2 & 1 & 1 & 0 & 0.75 \\
\hline 5 & 3 & 1 & 2 & 0 & 0 & 1 \\
\hline
\end{tabular}

$C R$ complete response, $P R$ partial response, $S D$ stable disease, $P D$ progressive disease, $O R R$ objective response rate

* For patients who underwent surgical resection and had a pathological confirmed complete response, treatment response was recorded as CR 
degrees of MSI. Baseline characteristics were comparable between the two groups (Table 1). However, ORR in instability-high group was significantly higher than ORR in instability-intermediate group (13/16 versus 6/17, $P=0.008$ ).

During a median follow-up of 11.2 months (range, 2.0-36.3), twelve patients had the disease progression. All patients remained alive at the wrighting of this article. Univariable analysis showed that the degree of microsatellite instability was associated with PFS after anti-PD-1 immunotherapy (Additional file 1: Table S1). Patients in instability-high subgroup have significant longer PFS (log-rank test, $P=0.004$, Fig. 1). After excluding

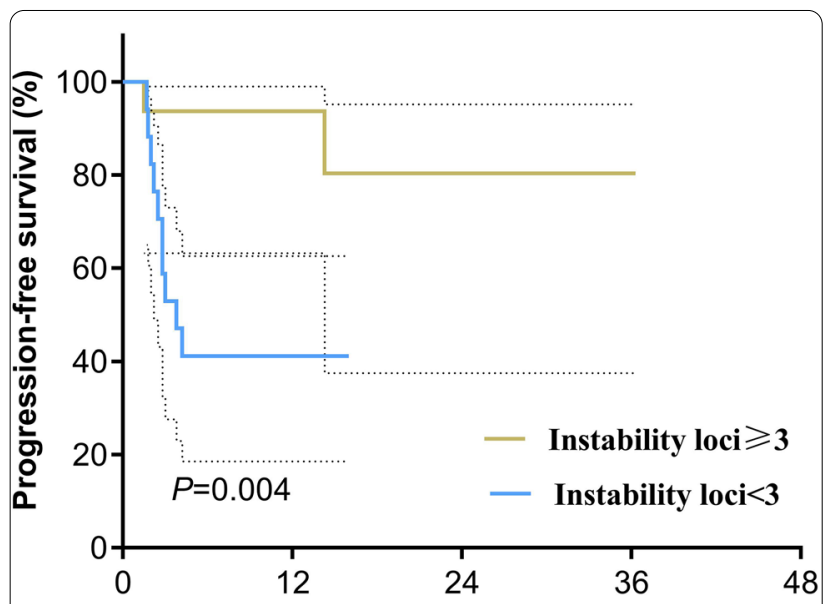

Time since start of anti-PD1 therapy (months)

Fig. 1 Progression-free survival of the two groups according to the degree of MSI. Survival was analyzed using the log-rank test. Dashed lines are $95 \%$ confidence intervals the confounding effects of sex, age and combined treatment by multivariate Cox proportional hazard model, instability-high was demonstrated to be an independent predictor for the longer PFS ( $\mathrm{HR}=0.136$ [0.024-0.781], $P=0.025$; Additional file 1: Table S2). Further univariable analysis of the location of the MSI loci showed that mutation in the loci of BAT25 and BAT26 were associated with longer PFS (Additional file 1: Table S3). To exclude the confounding effect of the number of instability loci, we did the multivariate cox regression for PFS, and BAT25 retains its predictive capability $(\mathrm{HR}=0.037$ [0.002-0.571], $P=0.018$; Additional file 1: Table S4).

IHC analyses of CD3 and CD8 were performed and the number of $\mathrm{CD} 3+$ and $\mathrm{CD} 8+\mathrm{T}$ cell infiltration per $\mathrm{mm}^{2}$ was counted in each group. A significant increase in $\mathrm{CD} 3+$ and $\mathrm{CD} 8+\mathrm{T}$ lymphocyte infiltration and cytolytic activity were also found in tumors in instability-high subgroup (Fig. 2).

\section{Discussion}

Our study indicated that the degree of microsatellite instability could predict a patient's response to antiPD-1 immunotherapy, and was an independent predictor for PFS in dMMR/MSI-H CRCs. This is in line with the recent finding in mouse models of microsatellite instability [6]. Underling mechanisms might involve the increased tumors immunogenicity and lymphocytic infiltration, as MSI-H reflects a genome-wide instability which eventually results in high mutational burden.

The main limitation of this study is the small sample size. But our data suggest that responds to anti-PD-1 are substantially diverse within $\mathrm{dMMR}$ tumors and that it highlights the possibility of more delicate selection for anti-PD-1 therapy in patients with dMMR/MSI-H.

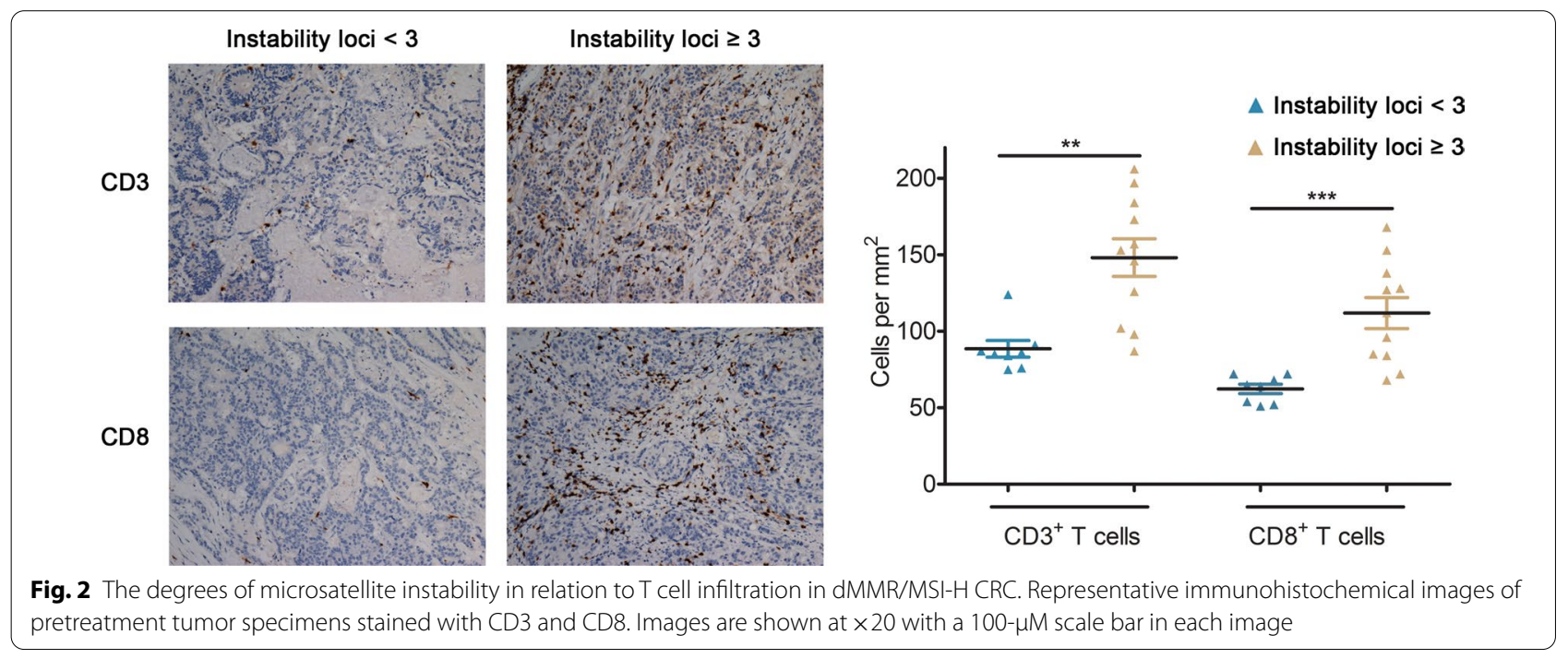




\section{Supplementary Information}

The online version contains supplementary material available at https://doi. org/10.1186/s40164-020-00193-z.

Additional file 1: Figure S1. The intensity of instability loci and the patient's response to anti-PD-1 treatment. A. The representative PCR result of the colorectal cancer patient (case 6) with five microsatellite instability loci. B. The representative MRI images of the patient (case 6) showing a sigmoid colon mass before and after anti-PD-1 immunotherapy. Table S1. Univariate analyses of the prognostic factors for progression-free survival of the cohort $(\mathrm{N}=33)$. Table $\mathbf{S 2}$. Multivariate Cox regression analyses of the prognostic factors for progression-free survival of the whole cohort $(\mathrm{N}=33)$. Table S3. Univariate analyses of the location of the MSI loci for progression-free survival of the cohort $(\mathrm{N}=33)$. Table S4. Multivariate Cox regression analyses for progression-free survival of the whole cohort $(\mathrm{N}=33)$.

\section{Abbreviations}

dMMR: Defects in DNA mismatch repair; MSI-H: Microsatellite instability-high; CRCs: Colorectal cancers; PD-1: Programmed cell death-1; PCR: Polymerase Chain Reaction; IHC: Immunohistochemistry; ORR: Objective response rate; CR: Complete response; PR: Partial response; PFS: Progression-free survival.

\section{Acknowledgements}

None.

\section{Authors' contributions}

DX and MYC designed the study. YHG, PRD, JPY, DX and MYC provided the material and technical support. QXW, CHQ and MYC analysed the data and drafted the manuscript. All authors read and approved the final manuscript.

\section{Funding}

This study was supported by the Grants from the Nature Science Foundation of China (Nos. 81672407 and 81872001) and the Program for physician-scientist in Sun Yat-sen University Cancer Center (No. 09010101).

\section{Availability of data and materials}

The datasets analysed during the current study are available from the corresponding author on reasonable request.

\section{Ethics approval and consent to participate}

The ethical committees in Sun Yat-sen University Center approved this study procedure and waive the necessity of informed consult for the retrospective design of this study.

\section{Consent for publication}

Not applicable.

\section{Competing interests}

All authors declare that they have no competing interests.

\section{Author details}

${ }^{1}$ Collaborative Innovation Center for Cancer Medicine, State Key Laboratory of Oncology in South China, Sun Yat-Sen University Cancer Center, No. 651 Dongfeng Road East, Guangzhou 510060, China. ${ }^{2}$ Department of Radiation Oncology, Sun Yat-Sen University Cancer Center, Guangzhou 510060, China. ${ }^{3}$ Department of Pathology, Sun Yat-Sen University Cancer Center, Guangzhou 510060, China. ${ }^{4}$ Department of Colorectal Surgery, Sun Yat-Sen University Cancer Center, Guangzhou 510060, China.

Received: 21 September 2020 Accepted: 27 November 2020 Published online: 04 January 2021

\section{References}

1. Kim TM, Laird PW, Park PJ. The landscape of microsatellite instability in colorectal and endometrial cancer genomes. Cell. 2013;155(4):858-68.

2. Le DT, Uram JN, Wang H, Bartlett BR, Kemberling H, Eyring AD, et al. PD-1 blockade in tumors with mismatch-repair deficiency. N Engl J Med. 2015;372(26):2509-20.

3. Overman MJ, Lonardi S, Wong KYM, Lenz HJ, Gelsomino F, Aglietta M, et al. Durable clinical benefit with nivolumab plus ipilimumab in DNA mismatch repair-deficient/microsatellite instability-high metastatic colorectal cancer. J Clin Oncol. 2018;36(8):773-9.

4. Overman MJ, McDermott R, Leach JL, Lonardi S, Lenz HJ, Morse MA, et al. Nivolumab in patients with metastatic DNA mismatch repair-deficient or microsatellite instability-high colorectal cancer (CheckMate 142): an open-label, multicentre, phase 2 study. Lancet Oncol. 2017;18(9):1182-91.

5. Le DT, Kim TW, Van Cutsem E, Geva R, Jäger D, Hara H, et al. Phase II openlabel study of pembrolizumab in treatment-refractory, microsatellite instability-high/mismatch repair-deficient metastatic colorectal cancer: KEYNOTE-164. J Clin Oncol. 2020;38(1):11-9.

6. Mandal R, Samstein RM, Lee KW, Havel JJ, Wang H, Krishna C, et al. Genetic diversity of tumors with mismatch repair deficiency influences anti-PD-1 immunotherapy response. Science. 2019;364(6439):485-91.

\section{Publisher's Note}

Springer Nature remains neutral with regard to jurisdictional claims in published maps and institutional affiliations.
Ready to submit your research? Choose BMC and benefit from:

- fast, convenient online submission

- thorough peer review by experienced researchers in your field

- rapid publication on acceptance

- support for research data, including large and complex data types

- gold Open Access which fosters wider collaboration and increased citations

- maximum visibility for your research: over 100M website views per year

At BMC, research is always in progress.

Learn more biomedcentral.com/submissions 